\title{
Proliferative cell nuclear antigen (PCNA) expression in the intestine of Salmo trutta trutta naturally infected with an acanthocephalan
}

Bahram Sayyaf Dezfuli ${ }^{1}$, Luisa Giari ${ }^{1}$, Alice Lui ${ }^{1}$, Samantha Squerzanti ${ }^{1}$, Giuseppe Castaldelli ${ }^{1}$, Andrew Paul Shinn ${ }^{2 *}$, Maurizio Manera ${ }^{3}$ and Massimo Lorenzoni ${ }^{4}$

\begin{abstract}
Background: Changes in the production of proliferating cell nuclear antigen (PCNA), a 36 kd protein involved in protein synthesis, within intestinal epithelia can provide an early indication of deviations to normal functioning. Inhibition or stimulation of cell proliferation and PCNA can be determined through immunohistochemical staining of intestinal tissue. Changes in the expression of PCNA act as an early warning system of changes to the gut and this application has not been applied to the fields of aquatic parasitology and fish health. The current study set out to determine whether a population of wild brown trout, Salmo trutta trutta (L.) harbouring an infection of the acanthocephalan Dentitruncus truttae Sinzar, 1955 collected from Lake Piediluco in Central Italy also effected changes in the expression of PCNA.
\end{abstract}

Methods: A total of 29 brown trout were investigated, 19 of which (i.e. 65.5\%) were found to harbour acanthocephalans $\left(5-320\right.$ worms fish $\left.{ }^{-1}\right)$. Histological sections of both uninfected and infected intestinal material were immunostained for PCNA.

Results: The expression of PCNA was observed in the epithelial cells in the intestinal crypts and within the mast cells and fibroblasts in the submucosa layer which is consistent with its role in cell proliferation and DNA synthesis. The number of PCNA-positive cells in both the intestinal epithelium and the submucosa layer in regions close to the point of parasite attachment were significantly higher than the number observed in uninfected individuals and in infected individuals in zones at least $0.7 \mathrm{~cm}$ from the point of parasite attachment (ANOVA, $p<0.05$ ).

Conclusions: An infection of the acanthocephalan D. truttae within the intestinal tract of S. t. trutta effected a significant increase in the number of PCNA positive cells (mast cells and fibroblasts) at the site of parasite attachment when compared to the number of positive cells found in uninfected conspecifics and in tissue zones away from the point of parasite attachment.

Keywords: Cell proliferation, Immunohistochemistry, Fish intestine, Enteric helminth.

\section{Background}

Changes in the rate of normal cell proliferation within the intestinal tract may serve as an early indication of abnormality. These changes are frequently screened in toxicity bioassays [1]. The intestinal epithelium undergoes rapid cell turnover and this renewal relies on intestinal stem cells situated in the crypt of the finger-like intestinal villi to generate new cells which

\footnotetext{
* Correspondence: aps1@stir.ac.uk

${ }^{2}$ Institute of Aquaculture, University of Stirling, Stirling, Scotland FK9 4LA UK Full list of author information is available at the end of the article
}

consequentially migrate along the axis of the villi [2]. Deregulation of intestinal cell proliferation and differentiation impairs the renewal of the intestinal epithelium that underlies many digestive diseases [2]. Cell proliferation can be detected by immunohistochemical staining of the proliferating cell nuclear antigen (PCNA) (see [3]), which is an evolutionary, highly conserved $36 \mathrm{kd}$ protein that is directly involved in DNA synthesis [4]. PCNA immuno-positivity is confined largely to the nuclei of dividing sperm cells, in ovarian follicles, lymphoid tissues of the kidneys, in neuronal cells of proliferative 
regions of the brain, epithelial cells of gill filaments, and, in the proliferative zones in the crypt regions of mucosal folds [5-7]. In teleosts, the presence of these proliferating cells at the base of intestinal folds have been described in Ctenopharyngodon idella (Valenciennes) [8] and in Barbus conchonius (F. Hamilton) [9].

In all vertebrates, the alimentary canal represents one of the primary routes of parasite and pathogen infection [10], and, therefore, serves as the primary barrier limiting or preventing the entry of harmful agents [11]. Under normal conditions, healthy fish are able to defend themselves against a broad spectrum of pathogens using a complex system of innate defence mechanisms [12]. The alimentary canal has a series of well-developed chemical and physical barriers which cooperate with an efficient, local, mucosal immune system [13]. Helminths comprise a diverse group of metazoan organisms consisting of several phyla and class of parasite presenting a vast array of differing morphologies, feeding strategies, behaviours and life-cycles [14,15], each exploiting a different niche within the intestinal environment. In a trade-off between host and parasite, many intestinal helminths have evolved mechanisms to evade their host's immune response, whilst the hosts have evolved a series of counter measures to deal with these [16]. As part of the infection process, certain intestinal helminths may induce structural modification to their host's tissues, and provoke alterations to the normal intestinal physiology [17]. In fish, the innate defences responding to helminth infection are associated with an inflammatory reaction $[10,18]$. Enteric helminths elicit an increase in the migration and accumulation of certain types of host immune cell (e.g., granulocytes) at the site of infection [18-20]. A histopathological approach paying particular attention to the cellular response initiated by the host in response to a helminth infection, which when combined with immunohistochemical methods, will provide a basis for the future elucidation on piscine antihelminthic responses [21].

This study examines changes in the number of PCNApositive cells in the intestine of a teleost fish infected with an enteric parasite. Specifically, the study looks at the number of proliferating cells seen in the immediate vicinity of an acanthocephalan attaching to the intestine of a brown trout, Salmo trutta trutta (L.), and compares them to the number observed away from the point of parasite attachment and in uninfected conspecifics.

\section{Results}

Of the 29 specimens of $S . t$. trutta $(32.27 \pm 5.71 \mathrm{~cm}$, mean total length \pm standard deviation [S.D.]) collected from Lake Piediluco, ten were uninfected and from the histological sections that were taken, the architectural integrity of the intestinal folds appeared to be intact (see Figure 1a). The remaining 19 (65.5\%) brown trout were infected with the acanthocephalan Dentitruncus truttae Sinzar, 1955 (Figure 1b) with the intensity of infection ranging from 5 to 320 worms per fish. The majority of worms were found in the median intestine. Generally, the acanthocephalans did not penetrate the stratum granulosum (Figures 1b, d, e), although occasionally a proboscis was observed to have penetrated the deeper layers causing disruption to the mucosa, lamina propria, stratum granulosum and the muscularis layers at the point of proboscis insertion (not shown). Dentitruncus truttae, with its numerous trunk spines, were observed in contact with the intestinal epithelium where they caused damage to the apices of villi (Figures 1b, d, e). The spines caused detachment of the epithelial cells and reduced the number of mucosal folds (Figure 1d). By comparison, the intestinal folds at sites at a distance of $0.7 \mathrm{~cm}$ or greater from the point of parasite attachment, remained intact (Figures 1b, d).

The intestinal mucosa of S. t. trutta is lined by a simple epithelium consisting of typical columnar epithelial cells with a sparse intermingling of mucous cells (Figure 1c). The response pattern for PCNA-positivity along the intestinal folds was common in the basal area of folds in both uninfected (Figure 1c) and acanthocephalan infected S. t. trutta (Figures 1d, e). Data from the immunohistochemical tests with the PCNA antiserum and positive cell counts are presented graphically in Figures 2 and 3.

No significant differences were observed in the number of PCNA positive nuclei in the intestinal sections taken from uninfected fish and from the infected trout but at a distance from the point of parasite attachment (ANOVA, $p>0.05$ ) (Figure 2). In infected fish, the number of PCNA-positive cells in the intestinal epithelium and/or the submucosa layer close to the site of parasite attachment (Figures 1d, e) were significantly higher than the numbers observed at points situated $0.7 \mathrm{~cm}$ or greater away from the point of parasite attachment (ANOVA, $p<0.05$ ) (Figure 3 ) and from uninfected individuals (ANOVA, $p<0.05$ ). Numerous PCNA-positive cells, for example, were observed in the lamina propriastratum granulosum in the immediate vicinity around the proboscis of D. truttae (Figures 1d, e). Parallel studies with light and electron microscopy have shown that these positive cells are mast cells (MCs; Figure 1f) these were the only positive type of leucocyte found. These cells are typically oval in shape, with an eccentric, polar nucleus, and a cytoplasm characterised by numerous large, membrane-bounded granules. Numerous MCs were seen within the stratum granulosum and in the muscularis layer, in close contact with capillaries. MCs were also observed in the outer layer of the endothelia, 

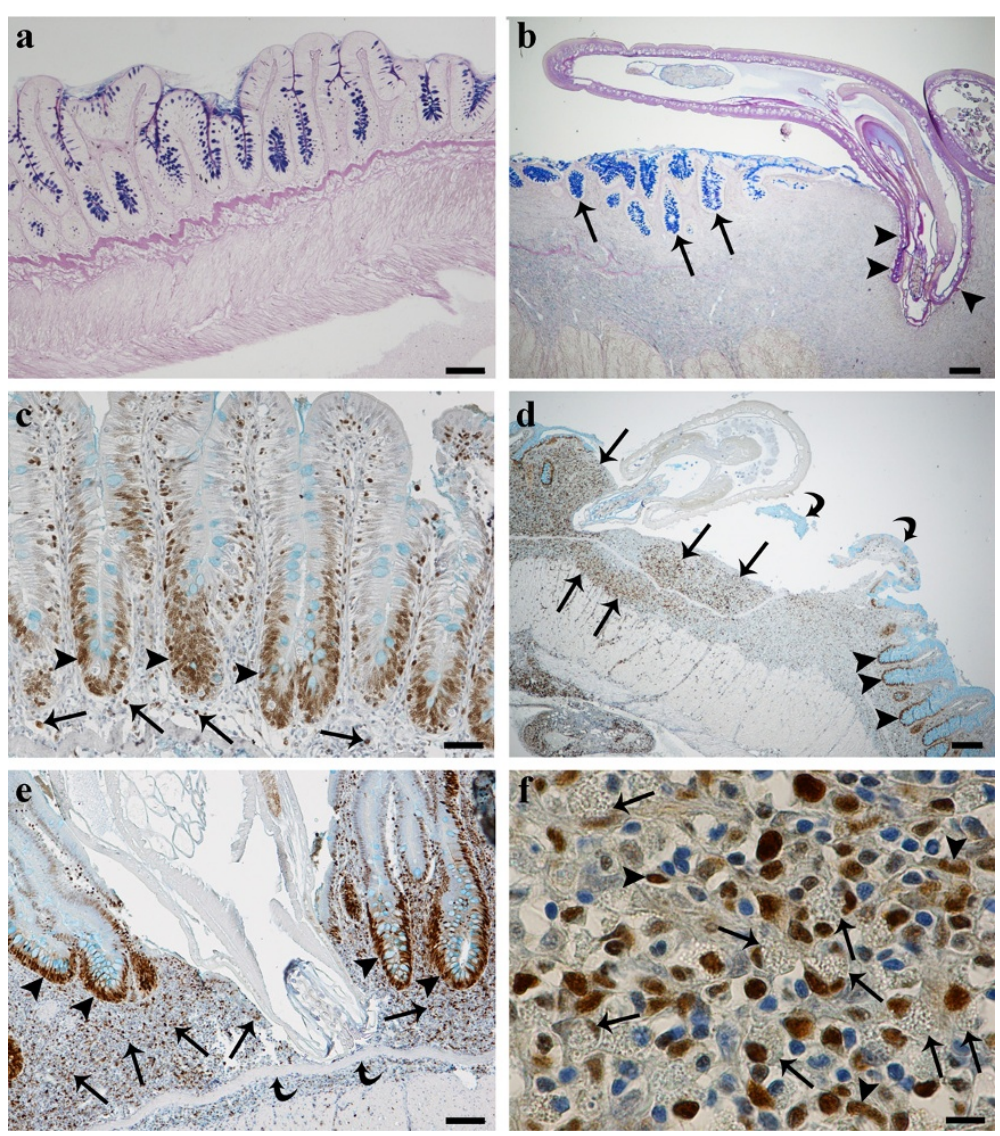

Figure 1 Histological sections through the intestines of Salmo trutta trutta L. (a) An H\&E stained section through an uninfected intestine where intact villi can be seen, scale bar $=100 \mu \mathrm{m}$. (b) Haematoxylin and eosin stained section of a trout intestine with an attached Dentitruncus truttae in situ. Note the spines on the trunk of the acanthocephalan (arrow heads) and the destruction of the villi at the site of attachment whilst those further away (arrows) are still intact, scale bar $=200 \mu \mathrm{m}$ (c-f) Immunohistochemistry. (c) Section through an uninfected intestine that has been stained with a PCNA-antibody. Positive cells (arrow heads) are localised deep within the intestinal folds. A small number of positive cells (arrows) are also visible within the sub-mucosal layer, scale bar $=50 \mu \mathrm{m}$. (d) Section through an infected brown trout intestine that has been stained with the PCNA-antibody. There is a lack of villi at the site of $D$. truttae attachment and numerous positive cells (arrows) within the submucosal layer are evident. Note the residual pieces of damaged intestinal fold (arrow heads). Numerous immunoreactive epithelial cells (curved arrows), however, are visible deep within the intestinal folds further away from the site of parasite attachment, scale bar $=200 \mu \mathrm{m}$. (e) An acanthocephalan with a proboscis which has not penetrated the stratum granulosum (curved arrow). Numerous PCNA-positive epithelial cells (arrow heads) are evident deep within the villi. Note the immunoreactive cells (arrows) within the sub-mucosal layer, scale bar $=50 \mu \mathrm{m}$. (f) A higher magnification of the lamina propria-stratum granulosum at a point in close proximity to the acanthocephalan proboscis where numerous PCNA-positive mast cells (arrows) and some positive fibroblasts (arrow heads) are evident, scale bar $=10 \mu \mathrm{m}$.

as well as inside blood vessels (not shown). MCs were frequently surrounded by fibroblasts and collagen fibres. Some fibroblasts were PCNA positive (Figure 1f), although it is interesting to note that positivity of these and MCs was influenced by their distance from the parasite (Figure 3). In infected fish, each cell type, and notably for the MCs and fibroblasts, the number of positive nuclei increased significantly (ANOVA, $p<0.01$ ) at the site of parasite attachment (Figure 3). In this study, the epithelial cells displayed higher PCNA positivity than the MCs and fibroblasts (ANOVA, $p<0.01$; Figure 2). There were no statistical differences in the number of MCs and fibroblasts (ANOVA, $p>0.05$; Figure 2).

\section{Discussion}

The PCNA is a ring-like protein that provides the DNA polymerase the processivity for DNA replication [22]. It is believed that the gene sequence and functions of PCNA are remarkably conserved among eukaryotes [23]. PCNA has been reported in several cell types in mammalian tissues and PCNA-positivity has been reported from a number of different organs in fish [2,3,24,25]. The aquatic environment is continuously exposed to a range of organic chemicals and there is growing concern in how each of these compounds affects the molecular and cellular mechanisms within the intestinal tract [26]. An increase in expression of PCNA is widely accepted 


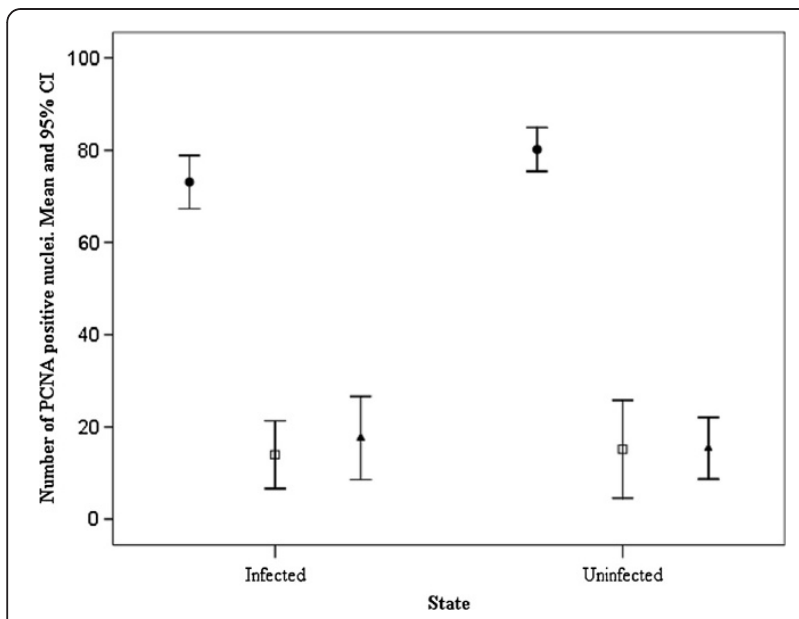

Figure 2 The mean number of PCNA positive nuclei in the intestines of uninfected Salmo trutta trutta and in infected hosts at a distance from the point of parasite attachment. Error bars represent $95 \%$ confidence intervals $(\mathrm{Cl})$ about the mean. Abbreviations: $\bullet$, epithelial cells; $\square$, mast cells; $\mathbf{\Lambda}$, fibroblasts.

as a marker of proliferation associated with the development of neoplastic tissue $[3,24,27,28]$. Teleost fish have, therefore, become a popular model for use in cancer studies, where there is growing interest on the concurrent detection of PCNA, tumour protein p53 and apoptosis $[23,29,30]$.

The stimulation or inhibition of normal cell proliferation, therefore, serves as an early indication of potential abnormality within the intestinal tract, making these an appropriate model for study in toxicity bioassays [1,31]. New intestinal epithelial cells are continuously produced

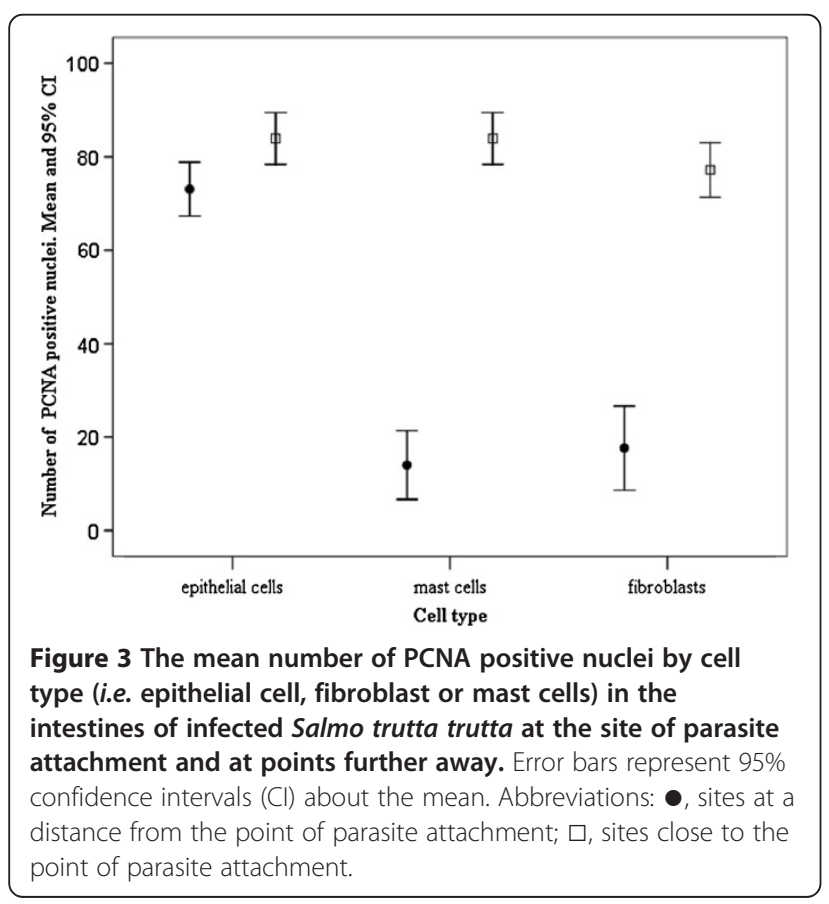

by stem cells in the crypts which subsequently migrate along the crypt-villi axis [26]. An increase in PCNA labelling, therefore, signals marked increases in the rate of cellular division. A number of experimental studies have examined the cellular localisation of PCNA within the intestines of fish exposed to a model toxicant [31] and through the dietary administration of compounds $[25,32,33]$, but no information exists regarding the expression of PCNA in infected fish tissues. The acanthocephalan D. truttae, in addition to its armed proboscis, bears trunk spines that facilitate its attachment within the intestinal villi of its fish host [34]. These spines, during the process of attachment, inflict damage to the intestinal folds, causing destruction of the villi epithelium resulting in the development of necrotic tissue. The immunohistochemical results demonstrate that the levels of acanthocephalan infection observed in the current study (i.e. 5-320 individuals fish ${ }^{-1}$ ) effect a significant increase in the number of PCNA-positive cells in the intestinal villi that are close to the sites of parasite attachment. The increase in PCNA-positive epithelial cells were observed within the villi crypts that were either occupied by or close to intestinal helminths, when compared to the lower numbers seen in uninfected fish or in villi that were situated at least $0.7 \mathrm{~cm}$ away from the site of helminth activity.

The extent of intestinal damage inflicted by acanthocephalans is related to the intensity of infection and the degree to which the parasite penetrate the host tissues $[35,36]$. Parasitic infection of the alimentary canal can have detrimental effects on digestive function [10,37], with many species of intestinal helminth inducing an inflammatory response at the site of attachment $[21,38]$. In fish, the innate defences in response to helminth infection are associated with inflammatory reactions $[10,18,39]$. The innate immunity of teleosts, involves a range of cell types, which commonly include MCs $[13,40,41]$. In perciform fish, it has been reported that the mast cells contain histamine, which can regulate the fish's inflammatory responses [42]. Moreover, MCs degranulation has been shown to promote intestinal contraction in Sparus aurata L. and in Oncorhynchus mykiss (Walbaum) [42,43].

Although Roberts et al. [44] introduced the term eosinophilic granule cell, there has been a tendency in recent years to use the term mast cell as these cells have functional and morphological similarities to [mammalian] MCs [45,46]. MCs are present in most species of teleost and are found in a variety of tissues, including the gastrointestinal tract, skin and gills [45-47]. MCs are motile $[19,48]$ and until recently, their origin was unclear but it is now known that in mammals their precursors are from pluripotent bone marrow-derived stem cells circulating in the blood and lymphatic fluid [49]. In 
fish, it is most likely that MCs differentiate in the haematopoietic organs and reach their target tissues via the circulatory system as immature cells [50], as has been reported for mammalian MCs [51].

Evidence of MCs migration has been documented in the gills of rainbow trout, O. mykiss, exposed to bacteria [52] and in the intestine of fish infected with tapeworms [53]. In all vertebrates, MCs may be strategically positioned at perivascular sites to regulate inflammatory responses [42,49]. This places them in a unique position to encounter invading organisms and to orchestrate a response [49]. In the current study, and in particular within the intestines of infected fish, numerous MCs were seen in close contact with capillaries and the outer layer of the endothelia as well as within the lumen of the blood vessels. MCs play an important role in responding to inflammation; their number increases in allergic reactions [49] and as a consequence of helminth infection [39,53-55]. The close association of MCs with the endothelial cells of capillaries and their presence within gill capillaries suggests that they may migrate across the endothelium $[47,52,54]$. Nonetheless, the intra-tissue migratory nature of $\mathrm{MCs}$ has been observed in the gills and intestine of fish $[48,56,57]$. In addition, the occurrence of MCs throughout the loose connective tissue of the gill arch, suggests that there is a resident population of these cells $[47,56]$. In the current study, numerous MCs were observed within the connective tissue, and both on the outside and within capillaries in the submucosal layers of infected brown trout intestines. Based on a considerable body of descriptive data, it is reasonable to presume that fish may have two populations of MCs, a circulating and a resident population, and the presence of parasites may induce recruitment of MCs to the site(s) of infection [18,20]. Accordingly, acute MC activation is a feature of many types of tissue injury; experimental studies have demonstrated that pathogen products can activate MCs [58].

In humans, PCNA-positive MCs have been observed in the nasal sub-epithelial and lamina propria layers in patients suffering allergic rhinitis [59]. A proliferation of mature MCs has also been reported in the nasal mucosa of those suffering allergies [60-62]. In the current study, a high number of PCNA-positive cells were seen in the sub-mucosal layer, immediately around the proboscis of $D$. truttae; most of these were MCs with some fibroblasts. The co-occurrence of fibres-fibroblasts and MCs has been described from a range of fish species including O. mykiss (see [50] Flaño et al. 1996), coho salmon, Oncorhynchus kisutch (Walbaum) (see [63]) and minnows, Phoxinus phoxinus L. (see [64]). It has been suggested that MCs have the potential to directly influence fibroblasts and/or indirectly influence other cells, leading to a profibrotic response [65]. Several lines of evidence suggest that MCs are involved in the fibrotic process and in tissue remodelling $[66,67]$. In the process of attachment, the proboscis of $D$. truttae penetrates deep into the sub-mucosal layer and destroys the architecture of the host's intestinal wall; the recruitment and proliferation of numerous MCs around the site of proboscis insertion may serve also to repair and remodel damaged intestinal tissue.

\section{Materials and methods}

During 2011, a total of 29 specimens of brown trout, $S$. t. trutta, were processed from Lake Piediluco (Province of Terni, Central Italy; $42^{\circ} 31^{\prime} 01^{\prime \prime} \mathrm{N} ; 12^{\circ} 45^{\prime} 00^{\prime \prime}$ E). The fish were caught by gill net that was deployed on two occasions by professional fishermen belonging to the Piediluco Fish Consortium. Immediately on landing, the fish were removed and transferred alive to the Consortium's facility where they were euthanased using an overdose of $125 \mathrm{mg} \mathrm{L}^{-1}$ MS222 (tricaine methanesulfonate, Sandoz, Basel, Switzerland). Thereafter, the spinal cord was severed and the fish lengthed and weighed. On post mortem, the fish were sexed before the digestive tract was removed and opened longitudinally in search of helminths. For parasites found still attached to the intestine, their exact position was recorded before a $15 \times 15 \mathrm{~mm}$ piece of tissue that surrounded the site of attachment was excised and then fixed in Bouin's for $10 \mathrm{~h}$. Thereafter, the fixed pieces of tissue were rinsed in several changes of $4^{\circ} \mathrm{C} 70 \%$ ethanol before being stored in the same medium until they were processed for histology. After fixation, the tissues were dehydrated through an alcohol series and then paraffin wax embedded using a Shandon Citadel 2000 Tissue Processor. After blocking out, $5 \mu \mathrm{m}$ thick sections were taken from each tissue block and the slides dried at $60^{\circ} \mathrm{C}$ for several hours. After dewaxing in xylene and rehydrated through a graded alcohol series, the slides were treated for antigen retrieval in citrate buffer $\mathrm{pH} 8.0$ for $20 \mathrm{~min}$ in a steamer bath at $95^{\circ} \mathrm{C}$; thereafter the slides were left for $10 \mathrm{~min}$ to cool to room temperature (RT). Endogenous peroxidase activity and non-specific staining were blocked respectively in $3 \% \mathrm{H}_{2} \mathrm{O}_{2}$ for $10 \mathrm{~min}$ and then in horse normal serum (1:20) for $30 \mathrm{~min}$. Commercially available antibody anti-PCNA (PC10 sc-56 mouse antirat IgG2a monoclonal antibody, Santa Cruz Biotechonology, Inc.), recommended for detection of PCNA in cells in a broad range of organisms including mammals, insects and yeasts, was used. Sections were incubated with the primary antibody (anti-PCNA diluted 1:500) for $2 \mathrm{~h}$ at RT. After washing with PBS, slides were incubated for $30 \mathrm{~min}$ with biotinylated horse anti-mouse serum (Vector, Burlingame, USA) followed by avidinconjugated horseradish peroxidase (Vector, Burlingame, USA). The enzyme activity was detected using DAB 
(3,3'-diaminobenzidine). Non immune mouse serum and diluent only sections were used as negative controls. Finally, the sections were dehydrated, counterstained with alcian blue and Harris' haematoxylin, mounted in Canada balsam, examined and photographed using a Nikon Microscope ECLIPSE 80i.

For comparative purposes, intestinal sections from ten acanthocephalan infected and ten uninfected trout were screened for PCNA positive cells. For each trout and each cell type (i.e. epithelial cells, mast cells and fibroblasts), 100 nuclei were assessed at $\times 400$ magnification and the ratio of PCNA positive nuclei were determined. In infected specimens, a nuclear count was made at the point of parasite attachment with a second count made $0.7 \mathrm{~cm}$ away; this approach allowed for differences in PCNA nuclear positivity due to helminth infection within the same host to be considered. Data, the number of PCNA positive nuclei, were assessed for normality by means of the Kolmogorov-Smirnov and Shapiro-Wilk tests. Parametric tests were subsequently applied and a generalised linear model for repeated measures was applied. Paired measures of PCNA positive cells in infected fish (at the site of infection and at a distance from it) were introduced in the model as repeated measures, whereas cell types (epithelial cells, mast cells and fibroblasts) were introduced in the model as fixed factors. Thus, differences between sites (at the site of attachment and at a distance from it), cell types (epithelial cells, mast cells, fibroblasts) and their interactions were evaluated. Moreover, a one way ANOVA was performed to detect significant differences in the number of positive cells determined from the uninfected and infected intestines (away from site of parasite attachment). The statistical package SPSS 14.0.2 and a $p<0.05$ level of significance were used throughout.

\section{Conclusions}

Changes in the production of PCNA within intestinal epithelia can provide an early indication of deviations to normal functioning. In brown trout, the number of PCNA-positive cells in both the intestinal epithelium and the submucosa layer in regions close to the point of Dentitruncus truttae attachment were significantly higher than the number observed in uninfected individuals and in infected individuals in zones away from the point of parasite attachment. The study also demonstrates the presence of PCNA positive mast cells and fibroblasts within the intestinal tissues of a fish.

\section{Abbreviations}

Cl: Confidence intervals; DAB: Diaminobenzidine; MCs: Mast cells; PBS: Phosphate buffered saline; PCNA: Proliferating cell nuclear antigen; RT: Room temperature; SD: Standard deviation.

\section{Competing interests}

The authors declare that they have no competing interests.

\section{Authors' contributions}

BSD performed field work, supervised the laboratory work and wrote the initial draft. LG, AL, SS, GC and MM collected data, performed field and laboratory work and analysed data. ML collected data and performed field work. APS intellectually supported the study and corrected the drafts of the manuscript. All authors read and approved the final manuscript.

\section{Acknowledments}

Thanks are due to F. Bisonni from the Fisheries Consortium of the Lake Piediluco for his assistance in collecting fish. This study was supported by grants from the Italian Ministry of the University and from Scientific Research and Technology.

\section{Author details}

'Department of Biology \& Evolution, University of Ferrara, St. Borsari 46, 44123 Ferrara, Italy. ${ }^{2}$ Institute of Aquaculture, University of Stirling, Stirling, Scotland FK9 4LA UK. ${ }^{3}$ Department of Food Science, University of Teramo, St. Crispi 212, 64100 Teramo, Italy. ${ }^{4}$ Department of Cellular and Environmental Biology, University of Perugia, St. Elce di Sotto 5, 06123 Perugia, Italy.

Received: 1 August 2012 Accepted: 2 September 2012 Published: 11 September 2012

\section{References}

1. Ortego LS, Hawkins WE, Walker WW, Krol RM, Benson WH: Immunohistochemical detection of proliferating cell nuclear antigen (PCNA) in tissues of aquatic animals utilized in toxicity bioassays. Mar Environ Res 1995, 39:271-273

2. Yang J, Chin YC, Jiang B, Yu X, Zhu G-Z, Chen Y, Barnard J, Mei W: hnRNP I inhibits notch signaling and regulates intestinal epithelial homeostasis in the zebrafish. PLoS Genet 2009, 5:e1000363.

3. Ortego LS, Hawkins WE, Walker WW, Krol RM, Benson WH: Detection of proliferating cell nuclear antigen in tissues of three small fish species. Biotech Histochem 1994, 69:317-323.

4. Mathews MB, Bernstein RM, Franza BR Jr, Garrels Jl: Identity of the proliferating cell nuclear antigen and cyclin. Nature 1984, 309:374-376.

5. Borucinska JD, Schmidt B, Tolisano J, Woodward D: Molecular markers of cancer in cartilaginous fish: immunocytochemical study of PCNA, p-53, myc and ras expression in neoplastic and hyperplastic tissues from free ranging blue sharks, Prionace glauca (L.). J Fish Dis 2008, 31:107-115.

6. Kong RYC, Giesy JP, Wu RSS, Chen EXH, Chiang MWL, Lim PL, Yuen BBH, Yip BWP, Mok HOL, Au DWT: Development of a marine fish model for studying in vivo molecular responses in ecotoxicology. Aquat Toxicol 2008, 86:131-141

7. Couillard CM, Laplatte B, Pelletier E: A fish bioassay to evaluate the toxicity associated with the ingestion of benzo[a]pyrene-contaminated benthic prey. Environ Toxicol Chem 2009, 28:772-781.

8. Stroband HW, Debets FM: The ultrastructure and renewal of the intestinal epithelium of the juvenile grasscarp, Ctenopharyngodon idella (Val.). Cell Tissue Res 1978, 187:181-200.

9. Rombout JHWM, Stroband HWJ, Taverne-Thiele JJ: Proliferation and differentiation of intestinal epithelial cells during development of Barbus conchonius (Teleostei, Cyprinidae). Cell Tissue Res 1984, 236:207-216.

10. Secombes CJ, Chappell LH: Fish immune responses to experimental and natural infection with helminth parasites. Annu Rev Fish Dis 1996, 6:167-177.

11. Niklasson L, Sundh H, Fridell F, Taranger GL, Sundell K: Disturbance of the intestinal mucosal immune system of farmed Atlantic salmon (Salmo salar), in response to long-term hypoxic conditions. Fish Shellfish Immunol 2011, 31:1072-1080.

12. Ellis AE: Innate host defence mechanisms of fish against viruses and bacteria. Dev Comp Immunol 2001, 25:827-839.

13. Rombout JHWM, Abelli L, Picchietti S, Scapigliati G, Kiron V: Teleost intestinal immunology. Fish Shellfish Immunol 2011, 31:616-626.

14. Reyes $\mathrm{J}$, Terrazas $\mathrm{Ll}$ : The divergent roles of alternatively activated macrophages in helminthic infections. Parasite Immunol 2007, 29:609-619.

15. Foster N, Elsheikha HM: The immune response to parasitic helminths of veterinary importance and its potential manipulation for future vaccine control strategies. Parasitol Res 2012, 110:1587-1599.

16. Sitjà-Bobadilla A: Living off a fish: a trade-off between parasites and the immune system. Fish Shellfish Immunol 2008, 25:358-372. 
17. Fairweather I: Peptides: an emerging force in host response to parasitism. In Parasites and pathogens: effects on host hormones and behaviour. Edited by Beckage NE. New York: Chapman \& Hall, International Thomson Publishing; 1997:113-139.

18. Butterworth AE: Cell-mediated damage to helminths. Adv Parasitol 1984, 23:143-235.

19. Reite $O B$, Evensen O: Inflammatory cells of teleostean fish: a review focusing on mast cells eosinophilic granule cells and rodlet cells. Fish Shellfish Immunol 2006, 20:192-208.

20. Alvarez-Pellitero P: Fish immunity and parasite infections: from innate immunity to immunoprophylactic prospects. Vet Immunol Immunopathol 2008, 126:171-198.

21. Buchmann K: Fish immune responses against endoparasitic nematodes experimental models. J Fish Dis, in press.J Fish Dis 2012, 35:623-635.

22. Kelman Z: PCNA: structure, functions and interactions. Oncogene 1997, 14:629-640

23. Leung AYH, Leung JCK, Chan LYY, Ma ESK, Kwan TTF, Lai KN, Meng A, Liang RA: Proliferating cell nuclear antigen (PCNA) as a proliferative marker during embryonic and adult zebrafish hematopoiesis. Histochem Cell Biol 2005, 124:105

24. Manera M, Biavati S: An immuno-histochemical technique used to demonstrate the transition form of a squamous cell carcinoma in a mirror carp, Cyprinus carpio L. J Fish Dis 1994, 17:93-96.

25. Olsvik PA, Torstensen BE, Berntssen MHG: Effects of complete replacement of fish oil with plant oil on gastrointestinal cell death, proliferation and transcription of eight genes' encoding proteins responding to cellular stress in Atlantic salmon Salmo salar L. J Fish Biol 2007, 71:550-568.

26. Sanden M, Olsvik PA: Intestinal cellular localization of PCNA protein and CYP1A mRNA in Atlantic salmon Salmo salar L. exposed to a model toxicant. BMC Physiol 2009, 9:3.

27. Bunton TE: Brown bullhead (Ameiurus nebulosus) skin carcinogenesis. Exp Toxic Pathol 2000, 52:209-220.

28. Haramis APG, Hurlstone A, van der Velden $Y$, Begthel $H$, van den Born $M$ Offerhaus GJA, Clevers HC: Adenomatous polyposis coli-deficient zebrafish are susceptible to digestive tract neoplasia. EMBO Rep 2006, 7:444-449.

29. Soutschek J, Zupanc GK: Apoptosis as a regulator of cell proliferation in the central posterior/prepacemaker nucleus of adult gymnotyform fish, Apteronotus leptorhyncus. Neurosci Lett 1995, 202:133-136.

30. Blas-Machado U, Taylor HW, Means JC: Apoptosis, PCNA, and p53 in Fundulus grandis fish liver after in vivo exposure to N-methyl-N'nitro-N-nitrosoguanidine and 2-aminofluorene. Toxicol Pathol 2000, 28:601-609.

31. Sanden M, Berntssen MHG, Krogdahl A, Hemre G-I, Bakke-McKellep A-M: An examination of the intestinal tract of Atlantic salmon, Salmo salar L., parr fed different varieties of soy and maize. J Fish Dis 2005, 28:317-330.

32. Van Veld PA, Vogelbein WK, Cochran MK, Goksøyr A, Stegeman JJ: Routespecific cellular expression of cytochrome P4501A (CYP1A) in fish (Fundulus heteroclitus) following exposure to aqueous and dietary benzo [a]pyrene. Toxicol Appl Pharmacol 1997, 142:348-59.

33. Basu N, Kennedy CJ, Hodson PV, Iwama GK: Altered stress responses in rainbow trout following a dietary administration of cortisol and $\beta$ napthoflavone. Fish Physiol Biochem 2001, 25:131-140.

34. Crompton DWT: The sites occupied by some parasitic helminths in the alimentary tract of vertebrates. Biol Rev 1973, 48:27-83.

35. Taraschewski H: Acanthocephala. In Fish diseases, vol. 2. Edited by Eiras JC Eb, Segner H, Wahli T, Kapoor BG. Enfield: Science Publishers; 2008:1025-1062.

36. Dezfuli BS, Castaldelli G, Bo T, Lorenzoni M, Giari L: Intestinal immune response of Silurus glanis and Barbus barbus naturally infected with Pomphorhynchus laevis (Acanthocephala). Parasite Immunol 2011, 33:116-123.

37. Hoste $\mathrm{H}$ : Adaptive physiological process in the host during gastrointestinal parasitism. Int J Parasitol 2001, 31:231-244.

38. Williams $\mathrm{H}$, Jones A: Parasitic worms of fishes. London: Taylor \& Francis Ltd; 1994.

39. Sharp GJE, Pike AW, Secombes CJ: The immune response of wild rainbow trout Salmo gairdneri Richardson to naturally acquired plerocercoid infections of Diphyllobothrium dendriticum (Nitzsch 1824) and D. ditremum (Creplin 1825). J Fish Biol 1989, 35:781-794.

40. Secombes CJ: Cellular defences in fish: an update. In Parasitic diseases of fish. Edited by Pike AW, Lewis JW. Dyfed: Samara Publishing; 1994:209-224.
41. Jones SRM: The occurrence and mechanisms of innate immunity against parasites in fish. Dev Comp Immunol 2001, 25:841-852.

42. Mulero I, Sepulcre MP, Meseguer J, Garcia-Ayala A, Mulero V: Histamine is stored in mast cells of most evolutionarily advanced fish and regulates the fish inflammatory response. P Natl Acad Sci USA 2007, 104:19434-19439.

43. Manera M, Giammarino A, Borreca C, Giari L, Dezfuli BS: Degranulation of mast cells due to compound 48/80 induces concentration-dependent intestinal contraction in rainbow trout (Oncorhynchus mykiss Walbaum) ex vivo. J Exp Zool Part A 2011, 315A:447-457.

44. Roberts RJ, Young $H$, Milne JA: Studies on the skin of plaice (Pleuronectes platessa L.) 1. The structure and ultrastructure of normal plaice skin. J Fish Biol 1972, 4:87-98.

45. Ellis AE: Eosinophilic granular cells (EGC) and histamine responses to Aeromonas salmonicida toxins in rainbow trout. Dev Comp Immunol 1985, 9:251-260.

46. Reite OB: The rodlet cells of teleostean fish: their potential role in host defence in relation to the role of mast cells/eosinophilic granule cells. Fish Shellfish Immunol 2005, 19:253-267.

47. Murray HM, Leggiadro CT, Douglas SE: Immunocytochemical localization of pleurocidin to the cytoplasmic granules of eosinophilic granular cells from the winter flounder gill. J Fish Bio/ 2007, 70:336-345.

48. Vallejo AN, Ellis AE: Ultrastructural study of the response of eosinophilic granule cells to Aeromonas salmonicida extracellular products and histamine liberators in rainbow trout, Salmo gairdneri Richardson. Dev Comp Immunol 1989, 13:133-148.

49. Mekori YA: The mastocyte: the "other" inflammatory cell in immunopathogenesis. J Allergy Clin Immunol 2004, 114:52-57.

50. Flaño E, Lopez-Fierro P, Razquin BE, Villena A: In vitro differentiation of eosinophilic granular cells in Renibacterium salmoninarum-infected gill cultures from rainbow trout. Fish Shellfish Immunol 1996, 6:173-184.

51. Kirshenbaum AS, Kessler SW, Goff JP, Metcalfe DD: Demonstration of the origin of human mast cells from $\mathrm{CD}_{3} 4^{+}$bone marrow progenitor cell. J Immunol 1991, 146:1410-1415.

52. Powell MD, Wright GM, Burka JF: Eosinophilic granule cells in the gills of rainbow trout, Oncorhynchus mykiss: evidence of migration? J Fish Biol 1990, 37:495-497.

53. Dezfuli BS, Giari L, Squerzanti A, Lui A, Lorenzoni M, Sakalli S, Shinn AP: Histological damage and inflammatory response elicited by Monobothrium wageneri (Cestoda) in the intestine of Tinca tinca (Cyprinidae). Parasit Vectors 2011, 4:225

54. Wanstall ST, Robotham PWJ, Thomas JS: Pathological changes induced by Pomphorhynchus laevis Muller (Acanthocephala) in the gut of rainbow trout, Salmo gairdneri Richardson. Parasitol Res 1986, 72:105-114.

55. Reite OB: Mast cells/eosinophilic granule cells of salmonids: staining properties and responses to noxious agents. Fish Shellfish Immunol 1997, 7:567-584.

56. Noya M, Lamas J: Response of eosinophilic granule cells of gilthead seabream (Sparus aurata, Teleostei) to bacteria and bacterial products. Cell Tissue Res 1997, 287:223-230.

57. Dezfuli BS, Giari L: Mast cells in the gills and intestines of naturally infected fish: evidence of migration and degranulation. J Fish Dis 2008 , 31:845-852.

58. Marshall JS, Jawdat DM: Mast cells in innate immunity. J Aller Clin Immunol 2004, 114:21-27.

59. Otsuka H, Kusumi T, Kanai S, Koyama M, Kuno Y, Takizawa R: Stem cell factor mRNA expression and production in human nasal epithelial cells: contribution to the accumulation of mast cells in the nasal epithelium of allergy. J Allergy Clin Immunol 1998, 102:757-764.

60. Tsai M, Takeishi T, Thompson H, Langley KE, Zsebo KM, Metcalfe DD, Geissler EN, Galli SJ: Induction of mast cell proliferation, maturation, and heparin synthesis by the rat c-kit ligand, stem cell factor. P Natl Acad SC USA 1991, 88:6382-6386.

61. Kawabori S, Kanai N, Tosho T: Proliferative activity of mast cells in allergic nasal mucosa. Clin Exp Allergy 1995, 25:173-178.

62. Bischoff SC, Sellge G, Lorentz A, Sebald W, Raab R, Manns MP: IL-4 enhances proliferation and mediator release in mature human mast cells. P Natl Acad Sci USA 1999, 96:8080-8085.

63. Kent ML, Powell MD, Kieser D, Hoskins GE, Speare DJ, Burka JF: Unusual eosinophilic granule cell proliferation in coho salmon (Oncorhynchus kisutch). J Comp Pathol 1993, 109:129-140. 
64. Dezfuli BS, Manera M, Giari L: Immune response to nematode larvae in the liver and pancreas of minnow, Phoxinus phoxinus (L.). J Fish Dis 2009, 32:383-390.

65. Puxeddu I, Piliponsky AM, Bachelet I, Levi-Schaffer F: Cells in focus. Mast cells in allergy and beyond. Int J Biochem Cell Biol 2003, 35:1601-1607.

66. Metcalfe DD, Baram D, Mekori YA: Mast cells. Physiol Rev 1997, 77:1033-1079.

67. Rocha JS, Chiarini-Garcia H: Mast cell heterogeneity between two different species of Hoplias sp. (Characiformes: Erythrinidae): response to fixatives, anatomical distribution, histochemical contents and ultrastructural features. Fish Shellfish Immunol 2007, 22:218-229.

doi:10.1186/1756-3305-5-198

Cite this article as: Dezfuli et al:: Proliferative cell nuclear antigen (PCNA) expression in the intestine of Salmo trutta trutta naturally infected with an acanthocephalan. Parasites \& Vectors 2012 5:198.

\section{Submit your next manuscript to BioMed Central and take full advantage of:}

- Convenient online submission

- Thorough peer review

- No space constraints or color figure charges

- Immediate publication on acceptance

- Inclusion in PubMed, CAS, Scopus and Google Scholar

- Research which is freely available for redistribution 